\title{
Microvascular function is impaired in ankylosing spondylitis and improves after tumour necrosis factor $\alpha$ blockade
}

\author{
I C van Eijk, ${ }^{1}$ M J L Peters, ${ }^{2}$ E H Serné, ${ }^{3}$ I E van der Horst-Bruinsma, ${ }^{2}$ B A C Dijkmans, ${ }^{1,2}$ \\ Y M Smulders, ${ }^{3}$ M T Nurmohamed ${ }^{1,2,3}$
}

${ }^{1}$ Department of Rheumatology, Jan van Breemen Institute, Amsterdam, The Netherlands; ${ }^{2}$ Department of Rheumatology, VU University Medical Center, Amsterdam, The Netherlands;

${ }^{3}$ Department of Internal Medicine and ICaR-VU, VU University Medical Center, Amsterdam, The Netherlands

Correspondence to: Dr M T Nurmohamed, Jan van Breemen Institute, Dr Jan van Breemenstraat 2, $1056 \mathrm{AB}$ Amsterdam, The Netherlands; m.nurmohamed@ janvanbreemen.nl

Accepted 30 March 2008 Published Online First 4 April 2008

\section{ABSTRACT}

Objectives: Ankylosing spondylitis (AS) is associated with increased cardiovascular morbidity and mortality. Microvascular function has been linked to several risk factors for cardiovascular disease. Inflammation in AS may cause microvascular dysfunction. To test this, we assessed microvascular function in (a) patients with AS compared to healthy controls and (b) patients with AS before and after 1 month of anti-tumour necrosis factor (TNF) $\alpha$ treatment with etanercept.

Methods: A total of 15 consecutive patients with AS, who were scheduled for etanercept treatment according to the Assessment in Ankylosing Spondylitis (ASAS) group guidelines, and 12 healthy controls matched for age and sex, were recruited. Endothelium-dependent and independent vasodilatation in skin were evaluated with laser Doppler fluxmetry after iontophoresis of acetylcholine and sodium nitroprusside, respectively.

Videomicroscopy was used to measure recruitment of skin capillaries after arterial occlusion.

Results: Compared to healthy controls, patients with AS had impaired endothelium-dependent vasodilatation and capillary recruitment. Following anti-TNF $\alpha$ treatment, microvascular function improved significantly for endothelium-dependent vasodilatation ( $p=0.03)$ and capillary recruitment $(p=0.006)$. A significant correlation was observed between changes in endothelium-dependent vasodilatation and changes in erythrocyte sedimentation rate (ESR) ( $r=-0.56 ; p=0.03)$.

Conclusion: Microvascular dysfunction is present in patients with AS with active disease, but improves as inflammation regresses after TNF $\alpha$ blockade.

Ankylosing spondylitis (AS) is a chronic inflammatory disease of the sacroiliac joints and spine affecting up to $1 \%$ of the population. ${ }^{1}$ Patients with AS have an approximately twofold increased death rate compared to the general population, which is predominately caused by increased cardiovascular (CV) risk..$^{2-4}$ Although specific cardiovascular disorders (valvular disease and conduction disturbances) occur more frequently in $\mathrm{AS},{ }^{4} 5$ accelerated atherosclerotic disease probably contributes to the increased CV risk as well. ${ }^{67}$ Accelerated atherosclerosis in AS may partly be due to traditional CV risk factors (ie, an atherogenic lipid profile and hypertension). ${ }^{89}$ In addition, the generalised inflammatory state that characterises active AS renders these patients more prone to develop cardiovascular, atherosclerotic, disease (CVD), as many parallels exist between the inflammatory mechanisms in the pathogenesis of atherosclerosis and in the pathogenesis of autoimmune diseases. ${ }^{10}$ Therefore, AS could be an independent cardiovascular risk factor. ${ }^{67}$ The association between inflammation and atherogenesis is most extensively described for rheumatoid arthritis (RA) and systemic lupus erythaematosus $^{11-14}$ but appears to apply to AS as well. ${ }^{67}$

Analogous to $\mathrm{RA}^{15}$ inflammation in AS may cause (microvascular) endothelial dysfunction. Endothelial dysfunction precedes and initiates atherosclerosis and is a predictor of long-term cardiovascular risk. ${ }^{16} \mathrm{~A}$ pivotal proinflammatory cytokine is tumour necrosis factor $\alpha$ (TNF $\alpha$ ). Circulating TNF $\alpha$ levels are increased in patients with AS and important in the pathogenesis of AS. ${ }^{17} 18$ Increased TNF $\alpha$ levels may have an important role in the pathogenesis of endothelial dysfunction in inflammatory diseases. ${ }^{19-21}$

A particularly interesting type of vascular dysfunction occurs in the microvasculature. Microvascular dysfunction is closely, and presumably causally, linked to CV risk factors, particularly insulin resistance and hypertension. ${ }^{22}{ }^{23}$ Preliminary evidence suggests that inflammation may also cause dysfunction of the microvasculature. Impaired coronary microvascular function was recently found in patients with AS, and correlated well with serum C-reactive protein (CRP) and TNF $\alpha$ levels. ${ }^{19}$ Interestingly, circulating levels of CRP and TNF $\alpha$ are associated with skin microvascular dysfunction even in normal subjects. ${ }^{24} 25$

Considering this, we hypothesised that patients with active AS have impaired microvascular function. In addition, we anticipate that blocking $\mathrm{TNF} \alpha$ in these patients not only reduces disease activity, ${ }^{26-29}$ but also improves microvascular function. To test this, we assessed capillary density and recruitment as well as endothelium-(in)dependent vasodilatation of skin microcirculation in (a) patients with AS compared to healthy controls and (b) patients with AS before and after 1 month of anti-TNF $\alpha$ treatment with etanercept.

\section{PATIENTS AND METHODS \\ Subjects}

A total of 15 consecutive patients with AS (10 males), scheduled for etanercept treatment according to the Assessment in Ankylosing Spondylitis (ASAS) group guidelines for anti-TNF $\alpha$ treatment ${ }^{30}$ were studied. All patients fulfilled the modified New York diagnostic criteria of $\mathrm{AS}^{31}$ and were recruited from the Jan van Breemen Institute and VU University Medical Center and treated with 
Table 1 Baseline characteristics of the patients with ankylosing spondylitis (AS) and healthy control subjects

\begin{tabular}{lll}
\hline & AS $(\mathbf{n}=\mathbf{1 5})$ & Controls $(\mathbf{n}=\mathbf{1 2})$ \\
\hline Age, years & $40(10)$ & $40(13)$ \\
Male, \% & 73 & 67 \\
Disease duration, years & $10.8(8.3)$ & \\
Smoking, \% & 47 & 42 \\
Systolic blood pressure, mmHg & $122(8)$ & $123(11)$ \\
Diastolic blood pressure, mmHg & $77(5)$ & $77(5)$ \\
Pulse pressure, mmHg & $44(7)$ & $46(9)$ \\
Body mass index & $26.9(24.2-28.2)$ & $23.2(22.2-24.9)$ \\
\hline
\end{tabular}

Data are mean (SD) or median (interquartile range); Student $t$ test or Mann-Whitney $\mathrm{U}$ test were used for comparing continuous variables. The Fisher exact test was used for dichotomous variables. Pulse pressure $=$ systolic blood pressure-diastolic blood pressure.

twice weekly $25 \mathrm{mg}$ etanercept subcutaneously. Exclusion criteria were (self-reported) diabetes mellitus, Raynaud phenomenon, thyroid dysfunction, previous cardiovascular events, hypertension (systolic blood pressure $>140 \mathrm{mmHg}$ and/or diastolic blood pressure $>90 \mathrm{mmHg}$ ) or the use of antihypertensive agents. A total of 12 age-matched and sex-matched healthy volunteers ( 8 males) served as controls. One patient and one control subject used a statin. No alterations in (concomitant) medication use, including non-steroidal anti-inflammatory drugs (NSAIDs), which all patients used, were allowed during the treatment period. All participants gave written informed consent and the study protocol was approved by the Institutional Ethics Committee of both hospitals.

\section{Study design}

Microvascular measurements were conducted in a quiet, temperature-controlled room $\left(T=23.4 \pm 0.4^{\circ} \mathrm{C}\right)$ after 20 30 min of acclimatisation, with the subjects in the sitting position and the investigated, non-dominant hand at heart level. Nailfold capillary studies and iontophoresis studies were performed on the same day. Subjects were asked to refrain from beverages other than water (especially no caffeine or alcohol), smoking, medication, except paracetamol if necessary, and meals from midnight on the testing day. During the tests, skin temperature was monitored and all subjects were studied between $8.00 \mathrm{am}$ and $12.00 \mathrm{am}$.

Nailfold capillaries in the dorsal skin of the third finger were visualised by a capillary microscope (Nikon, Amstelveen, The Netherlands), linked to a television camera (Philips LDH 0702/ 20; Eindhoven, The Netherlands), a video recorder (Panasonic NV-HS930, S-VHS; 's-Hertogenbosch, The Netherlands) and a monitor (Sony SSM-125CE; Badhoevedorp, The Netherlands). ${ }^{32}$ Incident illumination was achieved by light from a 100-W vapour mercury lamp (which passes through a heat-absorption and heat-reflection filter), a polariser and a $50 \%$ mirror to illuminate the object. To visualise the capillaries, a $5 \times$ objective (Nikon 5/0.13) was used with a total system magnification of $115 \times$. Nailfold capillaries in finger skin were recorded on videotape before and after 4 min of arterial occlusion with a digital cuff. This procedure was performed twice, and the mean of both measurements was used for analyses. Counting was performed using monitor (Sony PVM-1443MD) and video recorder (Sony S-VO-9500MDP). Capillaries were counted by a single observer using the naked eye from a freeze-framed reproduction of the videotape, and from the running videotape when it was uncertain whether a capillary was present or not. We estimated baseline capillary density by counting the number of continuously erythrocyte-perfused capillaries during a 15-s period. Other capillaries can be seen to be intermittently perfused, and these may represent an important functional reserve. We used postocclusive reactive hyperemia to estimate this functional reserve. Postocclusive capillary recruitment was calculated by dividing the increase in density by the baseline density. The day-to-day coefficient of variation (CoV) of the capillary density in resting state was $2.3(1.8) \%$. The CoV of the percentage capillary recruitment and absolute capillary recruitment during postocclusive hyperaemia were 8.3 (4.9)\% and 6.2 (4.3)\%, respectively.

Endothelium-(in)dependent vasodilatation of finger skin microcirculation was evaluated by iontophoresis of acetylcholine (ACh) and sodium nitroprusside in combination with laser Doppler fluxmetry as previously described in more detail. ${ }^{22} 33$ Laser Doppler fluxmetry measures microvascular perfusion, the product of red blood cell velocity and concentration. ${ }^{34} \mathrm{~A}$ protocol of multiple fixed doses (current intensity $\times$ delivery time) was employed resulting in an incremental dose-response curve. Acetylcholine (1\%, Miochol-E, Théa Pharma NV, Zoetemeer, The Netherlands) was delivered with an anodal current; seven doses ( $0.1 \mathrm{~mA}$ for $20 \mathrm{~s}$ ) were delivered, with a 60$\mathrm{s}$ interval between each dose. A 60 -s interval between each iontophoresis period was required to achieve the plateau of the response following each delivery of acetylcholine. ${ }^{35}$ Sodium nitroprusside (0.01\%, VU University Medical Center (VUmc)) was delivered with a cathodal current; nine doses $(0.2 \mathrm{~mA}$ for 20 s) were delivered, with a 90-s interval between each dose. A 90 -s interval between each iontophoresis period was required to achieve the plateau of the response after each delivery of sodium nitroprusside. ${ }^{35}$ Acetylcholine-dependent laser Doppler flux was measured on the middle phalanx of the third finger, whereas nitroprusside-dependent laser Doppler flux was measured at the same spot on the opposite hand, with approximately 15 min elapsed between the two measurements. The day-to-day CoV of the percentage increase from baseline to the final $2 \mathrm{~min}$ of the plateau phase was 9.8 (5.6)\% for acetylcholine and $8.3(5.4) \%$ for sodium nitroprusside.

\section{Statistical analyses}

Data are expressed as mean (SD) or median (interquartile range) as appropriate. The distribution of variables was tested for normality and transformed if necessary. Variables were tested (a) unpaired for comparing patients and controls and (b) paired

Table 2 Characteristics of patients with ankylosing spondylitis at baseline (AS pre) and after 1 month etanercept treatment (AS post)

\begin{tabular}{llll}
\hline & AS pre $(\mathbf{n}=\mathbf{1 5})$ & AS post $(\mathbf{n}=\mathbf{1 5})$ & $\mathbf{p}$ Value \\
\hline ESR, mm/h & $19(5-45)$ & $4(1-13)$ & $\mathbf{0 . 0 0 1}$ \\
CRP, mg/dl & $14(4-37)$ & $3(1-8)$ & $\mathbf{0 . 0 0 6}$ \\
BASDAl & $6.0(5.3-7.2)$ & $4.4(1.8-6.4)$ & $\mathbf{0 . 0 0 4}$ \\
BASFI & $5.2(4.0-6.3)$ & $3.2(1.7-5.1)$ & $\mathbf{0 . 0 0 3}$ \\
BASMI & $3.0(2.0-4.0)$ & $2.0(2.0-4.0)$ & 0.3 \\
Total cholesterol, mmol/ & $5.0(0.7)$ & $5.3(0.8)$ & $\mathbf{0 . 0 4}$ \\
litre & & & \\
HDL, mmol/litre & $1.3(0.4)$ & $1.4(0.3)$ & 0.05 \\
LDL, mmol/litre & $3.1(0.7)$ & $3.2(0.7)$ & 0.6 \\
TG, mmol/litre & $1.3(0.7)$ & $1.6(1.0)$ & 0.3 \\
\hline
\end{tabular}

Data are mean (SD) or median (interquartile range). Lipid profile was available for 13 patients (non-fasting). Figures in bold represent significant results.

BASDAI, Bath Ankylosing Spondylitis Disease Activity Index; BASFI, Bath Ankylosing Spondylitis Functional Index; BASMI, Bath Ankylosing Spondylitis Metrology Index; $\mathrm{CRP}, \mathrm{C}$-reactive protein; ESR, erythrocyte sedimentation rate; HDL, high-density lipoprotein; LDL, low-density lipoprotein; TG, triglyceride. 


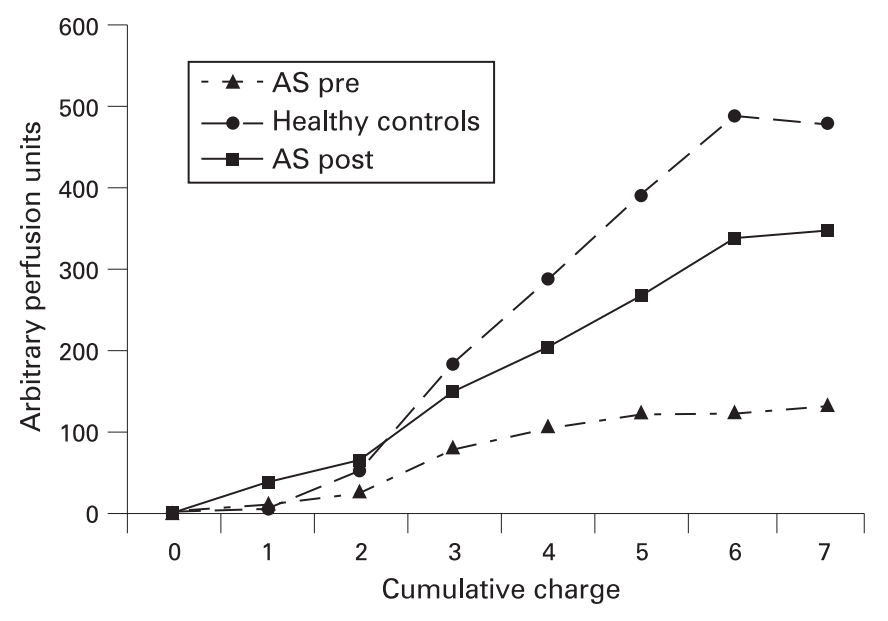

Figure 1 Perfusion changes in response to iontophoresis of acetylcholine in the patients with ankylosing spondylitis (AS) prior to treatment and post treatment and in the healthy control subjects. Baseline perfusion was set to $0 \%$ and every subsequent dot represents the percentage perfusion change compared to baseline. Every dot represents the median perfusion value of the $60 \mathrm{~s}$ between two subsequent pulses as described in the Patients and methods section.

for comparing the patients with AS at baseline and at 1 month. The Student t test was used to compare continuous normally distributed variables. We used non-parametric tests (Wilcoxon signed-rank test or Mann-Whitney U test) when appropriate. Linear regression analysis was used to investigate confounding by body mass index (BMI; as calculated using the formula weight $(\mathrm{kg}) /$ length $\left.(\mathrm{m})^{2} \times 100\right)$. A two-tailed probability value of $\mathrm{p}<0.05$ was considered statistically significant. Correlations between variables were analysed by using Pearson correlation or Spearman rho tests when appropriate.

\section{RESULTS}

\section{Characteristics}

Baseline characteristics of patients and controls are shown in tables 1 and 2. Age, sex, blood pressure and smoking status were similar in both groups. BMI was higher in patients compared to controls, 26.9 (24.2-28.4) vs 23.2 (22.2-24.9) respectively $(p=0.06)$. Within patients, BMI and blood pressure remained stable between the two time points. During treatment, CRP and erythrocyte sedimentation rate (ESR) levels, as well as Bath
Ankylosing Spondylitis Disease Activity Index (BASDAI) decreased significantly.

\section{Microvascular function is disturbed in AS}

At baseline, patients with AS showed a markedly lower vasodilatation in response to acetylcholine compared to controls ( $118 \%$ vs $469 \%$, respectively, $p=0.02$; table 3 and fig 1$)$. The response to sodium nitroprusside did not differ significantly between patients at baseline and 1 month and controls.

Baseline capillary density did not differ between groups. However, absolute and relative postischaemic capillary recruitment were lower in AS at baseline compared to controls (14.8 vs 19.5 , respectively for absolute increase, $p=0.04$ and $29.6 \%$ vs $39.2 \%$, respectively for relative increase, $p=0.01$ ). These results remained after separately adjusting for the difference in BMI and the difference in smoking status between the two groups (data not shown).

\section{Etanercept improves microvascular dysfunction}

After 1 month of treatment with etanercept, endotheliumdependent vasodilatation improved significantly in the patients with AS (from $118 \%$ to $318 \%, p=0.03$; table 3 and fig 1 ) and approached values observed in the healthy controls $(p=0.5)$. Capillary recruitment improved significantly in patients with AS during treatment (from 29.6\% to 38.9\%, p =0.006; table 3) to a level comparable to controls (38.9\% vs $39.2 \%$, respectively, $\mathrm{p}=1.0)$.

Etanercept-induced changes in endothelium-dependent vasodilatation correlated inversely with changes in ESR levels $(r=-0.56 p=0.03$, fig 2$)$. We did not find any significant correlations between pretreatment and post-treatment differences in endothelium-dependent vasodilatation relative to CRP $(r=-0.24 p=0.4$, fig 2$)$ or BASDAI $(r=-0.16 p=0.6)$. Changes in capillary recruitment (percentage) were not significantly correlated with changes in ESR, CRP or BASDAI $(\mathrm{r}=-0.15 \mathrm{p}=0.6, \mathrm{r}=0.014 \mathrm{p}=1.0, \mathrm{r}=0.50 \mathrm{p}=0.06$ respectively), although there was a trend for BASDAI.

\section{DISCUSSION}

The present study demonstrates that patients with active AS have impaired microvascular endothelium-dependent vasodilatation and capillary recruitment in skin, which improves after TNF $\alpha$-blocking therapy with etanercept.

Table 3 Microvascular measurements

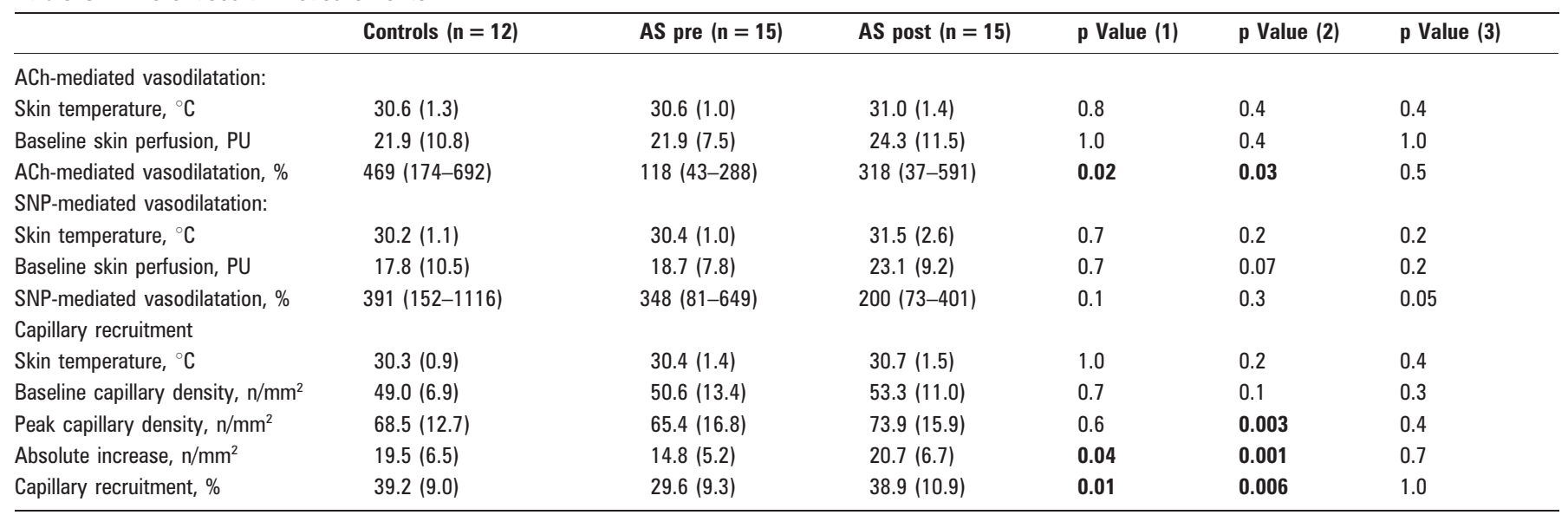



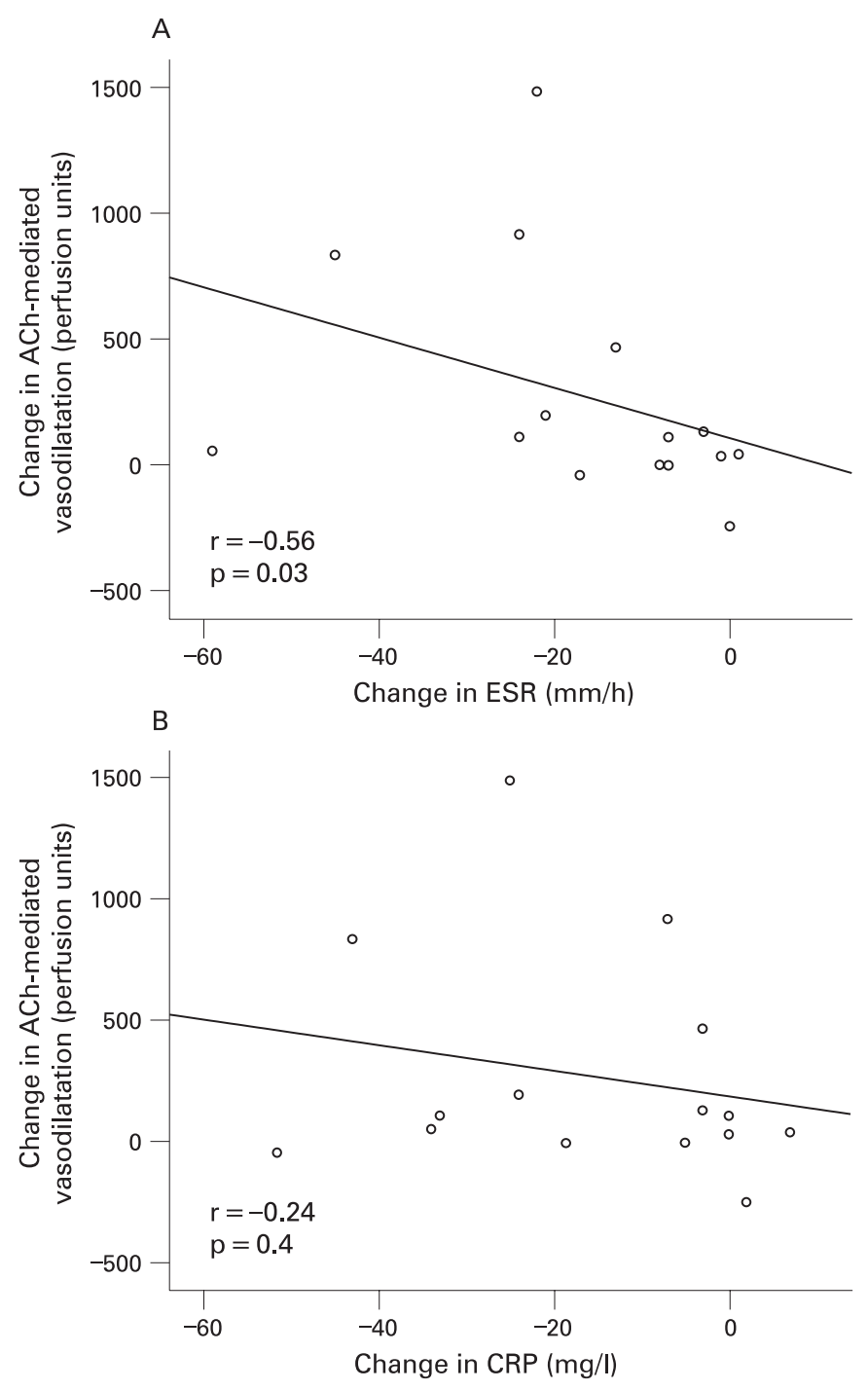

Figure 2 Correlation between changes in acetylcholine mediated vasodilatation (post/pretreatment, relative values) and changes in erythrocyte sedimentation rate (ESR) and C-reactive protein (CRP) levels.

Recent advances have highlighted the crucial involvement of the microcirculation in many cardiovascular conditions, not only in the development of target organ damage in the heart and kidney, but also in the development of cardiovascular risk factors such as hypertension and insulin resistance. ${ }^{23} 366^{37}$ Impaired microvascular endothelium-dependent vasodilatation and capillary recruitment, as measured in the present study, have been linked to several conditions associated with CVD, such as hypertension, insulin resistance and (visceral) obesity. $^{22} 232533$ Furthermore, impaired endothelium-dependent vasodilatation and capillary recruitment can be detected in individuals at increased coronary heart disease (CHD) risk according to the Framingham Heart Study risk score. ${ }^{38}$ The cutaneous microcirculation is a representative vascular bed to examine the mechanisms of microvascular dysfunction, which may mirror generalised systemic vascular dysfunction in magnitude and underlying mechanisms. ${ }^{39}$

The finding of impaired microvascular function in patients with AS is concordant with a previous study demonstrating impaired coronary microvascular function in patients with AS without any overt cardiovascular disease. ${ }^{19}$ Interestingly, in the latter study, impaired coronary microvascular function correlated well with CRP and TNF $\alpha$ levels, suggesting a detrimental effect of inflammation on the microcirculation. ${ }^{19}$ Our findings support this hypothesis by showing, for the first time, that blocking TNF $\alpha$ with etanercept, results in improvement of microvascular endothelium-dependent vasodilatation and even a normalisation of capillary recruitment in patients with AS compared to healthy controls. In patients with RA, the ability of TNF $\alpha$-blocking therapies to improve endothelial function has already been demonstrated, predominately at the macrovascular level, as measured by brachial artery ultrasonography ${ }^{21}$ or plethysmography. ${ }^{40}$ Again, in patients with RA, a case of diffusely impaired myocardial perfusion in the absence of any significant coronary atheroma in active systemic RA was described, which improved following intensive immunosuppression. ${ }^{41}$ Moreover, impaired endothelium-dependent vasodilatation has been shown at the microvascular level during active disease ("flare"), which improved after inflammatory suppression with disease-modifying antirheumatic drugs (DMARDs) or TNF $\alpha$-blocking therapy. ${ }^{42}$

In this regard, the observation of a lower incidence of first cardiovascular events in patients with RA treated with TNF $\alpha$ blocking therapy ${ }^{43}$ is interesting, as improvement of microvascular function after $T N F \alpha$ blockade may play a causative role.

There is evidence that $\mathrm{TNF} \alpha$ contributes to microvascular dysfunction. TNF $\alpha$ levels negatively correlate with skin capillary recruitment even in healthy individuals ${ }^{24} 25$ and increased production of TNF $\alpha$ is associated with obesity-related insulin resistance, as well as obesity-related hypertension. ${ }^{25}{ }^{44} \mathrm{~A}$ possible mechanism involved in these microvascular disturbances is impaired activation of endothelial nitric oxide synthase (eNOS). TNF $\alpha$ blocks the activation of eNOS, by interfering with Akt phosphorylation, which is essential for flow-dependent and ACh-dependent vasodilatation. ${ }^{45}$ In addition, TNF $\alpha$ directly degrades eNOS mRNA. ${ }^{46} 47$

In addition to specific TNF $\alpha$ effects on microvasculature, it is conceivable that, in line with inflammatory driven atherogenesis, improvement of microvascular function was the result of a generally decreased inflammatory "burden". Indeed, ESR and CRP levels, as markers of inflammation, declined significantly during treatment. In this regard, in 50 patients with psoriatic arthritis (another inflammatory disease included within the group of spondyloarthropathies) without clinically evident cardiovascular disease, a significant correlation between CRP level and ESR at the time of disease diagnosis and flow-mediated endothelial dependent vasodilatation was observed. ${ }^{48}$ Correlation analyses revealed a significant correlation for pretreatment and post-treatment ESR levels and endotheliumdependent vasodilatation, but not for CRP. The absence of a significant correlation between changes in CRP and vascular function was also reported in previous studies on vascular function in RA and AS. ${ }^{42} 49$ In our study, this may be due to small patient numbers or indicate that, in addition to inflammatory suppression, TNF $\alpha$ specific features determining endothelial function, are important. The latter is supported by a study showing improvement of endothelial function in patients with RA after intravascular administration of a TNF $\alpha$-blocking agent, without concurrently affecting circulating CRP levels. ${ }^{50}$ It is likely both mechanisms (ie, general dampening of inflammation and (other) TNF $\alpha$ specific effects) intertwine. The present study design, however, is not suited to clearly differentiate between these mechanisms.

In conclusion, we showed that patients with active AS have vascular dysfunction at the microcirculatory level. This finding supports the idea that AS represents a CHD risk factor. TNF $\alpha$ blocking therapy with etanercept improved microvascular 
function. Further research in larger patient groups should elucidate if this effect translates into a decrease in cardiovascular morbidity and mortality in patients with AS.

\section{Competing interests: None declared.}

Ethics approval: All participants gave written informed consent and the study protocol was approved by the Institutional Ethics Committee of both hospitals.

\section{REFERENCES}

1. Braun J, Bollow M, Remlinger G, Eggens U, Rudwaleit M, Distler A, et al. Prevalence of spondylarthropathies in HLA-B27 positive and negative blood donors. Arthritis Rheum 1998:41:58-67.

2. Lautermann D, Braun J. Ankylosing spondylitis - cardiac manifestations. Clin Exp Rheumatol 2002;20(Suppl 28):S11-S15.

3. Lehtinen K. Mortality and causes of death in 398 patients admitted to hospital with ankylosing spondylitis. Ann Rheum Dis 1993;52:174-6.

4. Peters MJ, van der Horst-Bruinsma IE, Dijkmans BA, Nurmohamed MT. Cardiovascular risk profile of patients with spondylarthropathies, particularly ankylosing spondylitis and psoriatic arthritis. Semin Arthritis Rheum 2004;34:585-92.

5. Roldan CA, Chavez J, Wiest PW, Qualls CR, Crawford MH. Aortic root disease and valve disease associated with ankylosing spondylitis. J Am Coll Cardiol 1998;32:1397-404.

6. Divecha H, Sattar N, Rumley A, Cherry L, Lowe GD, Sturrock R. Cardiovascular risk parameters in men with ankylosing spondylitis in comparison with non-inflammatory control subjects: relevance of systemic inflammation. Clin Sci (Lond) 2005;109:171-6.

7. Heeneman S, Daemen MJ. Cardiovascular risks in spondyloarthritides. Curr Opin Rheumatol 2007;19:358-62.

8. Alves MG, Espirito-Santo J, Queiroz MV, Madeira H, Macieira-Coelho E. Cardiac alterations in ankylosing spondylitis. Angiology 1988;39:567-71.

9. van Halm VP, van Denderen JC, Peters MJ, Twisk JW, van der PM, van der HorstBruinsma IE, et al. Increased disease activity is associated with a deteriorated lipid profile in patients with ankylosing spondylitis. Ann Rheum Dis 2006;65:1473-7.

10. Abou-Raya A, Abou-Raya S. Inflammation: a pivotal link between autoimmune diseases and atherosclerosis. Autoimmun Rev 2006;5:331-7.

11. Del Rincon I, Williams K, Stern MP, Freeman GL, O'Leary DH, Escalante A. Association between carotid atherosclerosis and markers of inflammation in rheumatoid arthritis patients and healthy subjects. Arthritis Rheum 2003:48:1833-40.

12. Gonzalez-Gay MA, Gonzalez-Juanatey C, Martin J. Rheumatoid arthritis: a disease associated with accelerated atherogenesis. Semin Arthritis Rheum 2005;35:8-17.

13. Roman MJ, Shanker BA, Davis A, Lockshin MD, Sammaritano L, Simantov R, et al. Prevalence and correlates of accelerated atherosclerosis in systemic lupus erythematosus. N Engl J Med 2003;349:2399-406.

14. Van Doornum S, McColl G, Wicks IP. Accelerated atherosclerosis: an extraarticular feature of rheumatoid arthritis? Arthritis Rheum 2002;46:862-73.

15. Vaudo G, Marchesi S, Gerli R, Allegrucci R, Giordano A, Siepi D, et al. Endothelial dysfunction in young patients with rheumatoid arthritis and low disease activity. Ann Rheum Dis 2004;63:31-5.

16. Yeboah J, Crouse JR, Hsu FC, Burke GL, Herrington DM. Brachial flow-mediated dilation predicts incident cardiovascular events in older adults: the Cardiovascular Health Study. Circulation 2007;115:2390-7.

17. Braun J, Sieper J, Breban M, Collantes-Estevez E, Davis J, Inman R, et al. Antitumour necrosis factor $\alpha$ therapy for ankylosing spondylitis: international experience. Ann Rheum Dis 2002;61(Suppl 3):iii51-iii60.

18. Gratacos J, Collado A, Filella X, Sanmarti R, Canete J, Llena J, et al. Serum cytokines (IL-6, TNF- $\alpha$, IL-1 $\beta$ and IFN- $\gamma$ ) in ankylosing spondylitis: a close correlation between serum IL-6 and disease activity and severity. Br J Rheumatol 1994;33:927-31.

19. Caliskan M, Erdogan D, Gullu H, Yilmaz S, Gursoy Y, Yildirir A, et al. Impaired coronary microvascular and left ventricular diastolic functions in patients with ankylosing spondylitis. Atherosclerosis 2008;196:306-12.

20. Gonzalez-Juanatey C, Testa A, Garcia-Castelo A, Garcia-Porrua C, Llorca J, Gonzalez-Gay MA. Active but transient improvement of endothelial function in rheumatoid arthritis patients undergoing long-term treatment with anti-tumor necrosis factor $\alpha$ antibody. Arthritis Rheum 2004;51:447-50.

21. Hurlimann D, Forster A, Noll G, Enseleit F, Chenevard R, Distler O, et al. Anti-tumor necrosis factor- $\alpha$ treatment improves endothelial function in patients with rheumatoid arthritis. Circulation 2002;106:2184-7.

22. Serne EH, Stehouwer CD, ter Maaten JC, ter Wee PM, Rauwerda JA, Donker AJ, et al. Microvascular function relates to insulin sensitivity and blood pressure in normal subjects. Circulation 1999;99:896-902.

23. Serne EH, de Jongh RT, Eringa EC, IJzerman RG, Stehouwer CD. Microvascular dysfunction: a potential pathophysiological role in the metabolic syndrome. Hypertension 2007:50:204-11.

24. de Jongh RT, IJzerman RG, Serne EH, Voordouw JJ, Yudkin JS, de Waal HA, et al. Visceral and truncal subcutaneous adipose tissue are associated with impaired capillary recruitment in healthy individuals. J Clin Endocrinol Metab 2006;91:5100-6.
25. Ijzerman RG, Voordouw JJ, van Weissenbruch MM, Yudkin JS, Serne EH, Delemarre-van de Waal HA, et al. TNF- $\alpha$ levels are associated with skin capillary recruitment in humans: a potential explanation for the relationship between TNF- $\alpha$ and insulin resistance. Clin Sci (Lond) 2006;110:361-8.

26. Braun J, Brandt J, Listing J, Zink A, Alten R, Golder W, et al. Treatment of active ankylosing spondylitis with infliximab: a randomised controlled multicentre trial. Lancet 2002:359:1187-93.

27. Calin A, Dijkmans BA, Emery P, Hakala M, Kalden J, Leirisalo-Repo M, et al. Outcomes of a multicentre randomised clinical trial of etanercept to treat ankylosing spondylitis. Ann Rheum Dis 2004;63:1594-600.

28. Gorman JD, Sack KE, Davis JC Jr. Treatment of ankylosing spondylitis by inhibition of tumor necrosis factor $\alpha$. N Engl J Med 2002;346:1349-56.

29. van der Heijde D, Kivitz A, Schiff MH, Sieper J, Dijkmans BA, Braun J, et al. Efficacy and safety of adalimumab in patients with ankylosing spondylitis: results of a multicenter, randomized, double-blind, placebo-controlled trial. Arthritis Rheum 2006;54:2136-46.

30. Braun J, Davis J, Dougados M, Sieper J, van der LS, van der HD. First update of the international ASAS consensus statement for the use of anti-TNF agents in patients with ankylosing spondylitis. Ann Rheum Dis 2006;65:316-20.

31. van der Linden S, Valkenburg HA, Cats A. Evaluation of diagnostic criteria for ankylosing spondylitis. A proposal for modification of the New York criteria. Arthritis Rheum 1984;27:361-8.

32. Bollinger AFBE. Clinical capillaroscopy. A guide to its use in clinical research and practice. Stuttgart, Germany: Hofgrefe \& Huber Publishers, 2007.

33. Serne EH, Gans RO, ter Maaten JC, ter Wee PM, Donker AJ, Stehouwer CD. Capillary recruitment is impaired in essential hypertension and relates to insulin's metabolic and vascular actions. Cardiovasc Res 2001;49:161-8.

34. Borgos J. Laser Doppler flowmetry: theory and practice. London, UK: Med-Orion Publishing Company, 2003.

35. Morris SJ, Shore AC, Tooke JE. Responses of the skin microcirculation to acetylcholine and sodium nitroprusside in patients with NIDDM. Diabetologia 1995;38:1337-44.

36. Cheung N, Bluemke DA, Klein R, Sharrett AR, Islam FM, Cotch MF, et al. Retinal arteriolar narrowing and left ventricular remodeling: the multi-ethnic study of atherosclerosis. J Am Coll Cardiol 2007;50:48-55.

37. Struijker-Boudier HA, Rosei AE, Bruneval P, Camici PG, Christ F, Henrion D, et al. Evaluation of the microcirculation in hypertension and cardiovascular disease. Eur Heart J 2007:8:2834-40.

38. ljzerman RG, de Jongh RT, Beijk MA, van Weissenbruch MM, Delemarre-van de Waal HA, Serne EH, et al. Individuals at increased coronary heart disease risk are characterized by an impaired microvascular function in skin. Eur J Clin Invest 2003;33:536-42.

39. Holowatz LA, Thompson-Torgerson CS, Kenney WL. The cutaneous circulation as a model of generalized microvascular function. J Appl Physiol 2008;105:373-4.

40. Bergholm R, Leirisalo-Repo M, Vehkavaara S, Makimattila S, Taskinen MR, YkiJarvinen $\mathrm{H}$. Impaired responsiveness to NO in newly diagnosed patients with rheumatoid arthritis. Arterioscler Thromb Vasc Biol 2002;22:1637-41.

41. Raza K, Banks M, Kitas GD. Reversing myocardial microvascular disease in a patient with rheumatoid arthritis. J Rheumatol 2005;32:754-6.

42. Datta D, Ferrell WR, Sturrock RD, Jadhav ST, Sattar N. Inflammatory suppression rapidly attenuates microvascular dysfunction in rheumatoid arthritis. Atherosclerosis 2007;192:391-5.

43. Jacobsson LT, Turesson C, Gulfe A, Kapetanovic MC, Petersson IF, Saxne T, et al. Treatment with tumor necrosis factor blockers is associated with a lower incidence of first cardiovascular events in patients with rheumatoid arthritis. J Rheumatol 2005;32:1213-18.

44. Pausova Z, Deslauriers B, Gaudet D, Tremblay J, Kotchen TA, Larochelle P, et al. Role of tumor necrosis factor- $\alpha$ gene locus in obesity and obesity-associated hypertension in French Canadians. Hypertension 2000;36:14-19.

45. Dimmeler S, Fleming I, Fisslthaler B, Hermann C, Busse R, Zeiher AM. Activation of nitric oxide synthase in endothelial cells by Akt-dependent phosphorylation. Nature 1999;399:601-5.

46. Cardaropoli S, Silvagno F, Morra E, Pescarmona GP, Todros T. Infectious and inflammatory stimuli decrease endothelial nitric oxide synthase activity in vitro. J Hypertens 2003;21:2103-10.

47. Yoshizumi M, Perrella MA, Burnett JC Jr, Lee ME. Tumor necrosis factor downregulates an endothelial nitric oxide synthase mRNA by shortening its half-life. Circ Res 1993;73:205-9.

48. Gonzalez-Juanatey C, Llorca J, Miranda-Filloy JA, Amigo-Diaz E, Testa A, GarciaPorrua C, et al. Endothelial dysfunction in psoriatic arthritis patients without clinically evident cardiovascular disease or classic atherosclerosis risk factors. Arthritis Rheum 2007; 57:287-93.

49. Sari I, Okan T, Akar S, Cece H, Altay C, Secil M, et al. Impaired endothelial function in patients with ankylosing spondylitis. Rheumatology (Oxford) 2006;45:283-6.

50. Cardillo C, Schinzari F, Mores N, Mettimano M, Melina D, Zoli A, et al. Intravascular tumor necrosis factor $\alpha$ blockade reverses endothelial dysfunction in rheumatoid arthritis. Clin Pharmacol Ther 2006;80:275-81. 


\title{
ARD
}

\section{Microvascular function is impaired in ankylosing spondylitis and improves after tumour necrosis factor $\alpha$ blockade}

\author{
I C van Eijk, M J L Peters, E H Serné, et al.
}

Ann Rheum Dis 2009 68: 362-366 originally published online April 4, 2008

doi: 10.1136/ard.2007.086777

Updated information and services can be found at:

http://ard.bmj.com/content/68/3/362.full.html

\begin{tabular}{|c|c|}
\hline & These include: \\
\hline References & $\begin{array}{l}\text { This article cites } 48 \text { articles, } 21 \text { of which can be accessed free at: } \\
\text { http://ard.bmj.com/content/68/3/362.full.html\#ref-list- } 1\end{array}$ \\
\hline & $\begin{array}{l}\text { Article cited in: } \\
\text { http://ard.bmj.com/content/68/3/362.full.html\#related-urls }\end{array}$ \\
\hline $\begin{array}{l}\text { Email alerting } \\
\text { service }\end{array}$ & $\begin{array}{l}\text { Receive free email alerts when new articles cite this article. Sign up in } \\
\text { the box at the top right corner of the online article. }\end{array}$ \\
\hline $\begin{array}{r}\text { Topic } \\
\text { Collections }\end{array}$ & $\begin{array}{l}\text { Articles on similar topics can be found in the following collections } \\
\text { Immunology (including allergy) (45820 articles) } \\
\text { Inflammation ( } 13893 \text { articles) } \\
\text { Ankylosing spondylitis ( } 471 \text { articles) } \\
\text { Connective tissue disease ( } 7718 \text { articles) } \\
\text { Degenerative joint disease ( } 9987 \text { articles) } \\
\text { Musculoskeletal syndromes ( } 18049 \text { articles) } \\
\text { Rheumatoid arthritis (3809 articles) } \\
\text { Epidemiology ( } 5680 \text { articles) } \\
\text { Calcium and bone (6568 articles) }\end{array}$ \\
\hline
\end{tabular}

Notes

To request permissions go to:

http://group.bmj.com/group/rights-licensing/permissions

To order reprints go to:

http://journals.bmj.com/cgi/reprintform

To subscribe to BMJ go to:

http://group.bmj.com/subscribe/ 